\begin{tabular}{|c|l|}
\hline Title & $\begin{array}{l}\text { Estimation of Evolutionary Rates of Mitochondrial DNA in Two Japanese Wood Mouse Species Based on Calibrations } \\
\text { with Quaternary Environmental Changes }\end{array}$ \\
\hline Author(s) & $\begin{array}{l}\text { Hanazaki, Kaori; Tomozawa, Morihiko; Suzuki, Yutaro; Kinoshita, Gohta; Y amamoto, Masanobu; Irino, Tomohisa; } \\
\text { Suzuki, Hitoshi }\end{array}$ \\
\hline Citation & $\begin{array}{l}\text { Zoological science, 34(3), 201-210 } \\
\text { https://doi.org/10.2108/2s160169 }\end{array}$ \\
\hline Issue Date & 2017-06 \\
\hline Doc URL & http://hdl.handle.net/2115/70653 \\
\hline Type & article \\
\hline File Information & zs160169.pdf \\
\hline
\end{tabular}

Instructions for use 


\title{
Estimation of Evolutionary Rates of Mitochondrial DNA in Two Japanese Wood Mouse Species Based on Calibrations with Quaternary Environmental Changes
}

\author{
Kaori Hanazaki ${ }^{1}$, Morihiko Tomozawa ${ }^{2}$, Yutaro Suzuki ${ }^{1}$, Gohta Kinoshita', \\ Masanobu Yamamoto', Tomohisa Irino', and Hitoshi Suzuki ${ }^{1 *}$ \\ ${ }^{1}$ Graduate School of Environmental Science, Hokkaido University, Kita-ku, Sapporo 060-0810, Japan \\ ${ }^{2}$ Department of Biology, Keio University, Yokohama 223-8521, Japan
}

\begin{abstract}
Reliable estimates of evolutionary rates of mitochondrial DNA might allow us to build realistic evolutionary scenarios covering broad time scales based on phylogenetic inferences. In the present study, we sought to obtain estimates of evolutionary rates in murine rodents using calibrations against historical biogeographic events. We first assumed that land-bridge-like structures that appeared intermittently at glacial maxima with 100,000-year intervals shaped the divergence patterns of cytochrome $b$ (Cytb) sequences (1140 bp) of the larger Japanese wood mouse Apodemus speciosus. The comparison of sequences from peripheral remote islands that are separated from one another by deep straits allowed us to estimate mitochondrial DNA evolutionary rates (substitutions/site/million years) to be 0.027 to 0.036 , with presumed calibrations from $140,000,250,000$, 350,000 , and 440,000 years ago. Second, we addressed rapid expansion events inferred from analyses of the Cytb sequences of the lesser Japanese wood mouse $A$. argenteus. We detected five expansion signals in the dataset and established three categories based on the expansion parameter tau values: $3.9,5.6-5.7$, and $7.8-8.1$. Considering that the climate became warmer 15,000 , 53,000 , and 115,000 years ago after preceding periods of rapid cooling, we calculated evolutionary rates to be $0.114,0.047$, and 0.031 , respectively. This preliminary concept of the evolutionary rates on a time scale from 15,000 to 440,000 years ago for the wood mouse should be refined and tested in other species of murine rodents, including mice and rats.
\end{abstract}

Key words: mitochondrial DNA, time-dependent evolutionary rate, wood mice, Quaternary ice ages, the Japanese Islands

\section{INTRODUCTION}

There are several barriers to obtaining reliable evolutionary rates for mitochondrial DNA (mtDNA), the most commonly used phylogenetic marker. However, determination of the rate of evolution of mtDNA is necessary for assessing the temporal aspect of phylogenetic inference. Anchoring sites (calibrations) for certain geological times are generally established with the aid of fossil evidence, but it is difficult to obtain reliable fossil records for most taxa. In addition, the evolutionary rates of mtDNA reportedly differ among taxa, such as insects, reptiles, birds, and mammals (Ho et al., 2015; Molak and Ho, 2015), and even between mammalian taxa, such as rodents and other larger groups. Moreover, the short-term evolutionary rates of mtDNA are time-dependent; a higher molecular rate is estimated for a shorter sampling time (e.g., Ho and Larson, 2006; Howell et al., 2008; Galtier et al., 2009; Ho et al., 2011). In intraspecies comparisons of the cytochrome $b$ gene (Cytb) sequence among rodents, for example, high rates, such as 0.30 substitutions/site/million years (my) (Martínková et al., 2013) and 0.46 substitutions/

\footnotetext{
* Corresponding author. E-mail: htsuzuki@ees.hokudai.ac.jp doi:10.2108/zs160169
}

site/my (Herman et al., 2014), have been predicted. These are markedly higher than the commonly used rates for interspecies comparisons, such as 0.024 substitutions/site/my (Suzuki et al., 2003). The patterns that characterize the timedependency of evolutionary rates remain unknown, and further study is needed to assess the validity of this hypothesis, so that molecular phylogenetic inference can be performed with more reliable estimations of the rate of evolution ( $\mathrm{Ho}$ et al., 2011).

Other than the use of fossil evidence, another possible approach to the assessment of molecular evolutionary rates is to seek biogeographic calibrations; i.e., to identify links between the genetic divergences of focus and their associated geological events or historical events that could serve as calibration points (e.g., Ho et al., 2011, 2015; Crandall et al., 2012; Martínková et al., 2013; Herman et al., 2014; Suzuki et al., 2015). One way of estimating evolutionary rates is instantaneous geological association between insular populations (Ho et al., 2015). High-resolution records of global sea levels during the Quaternary ice ages are available (Lambeck et al., 2002; Lisiecki and Raymo, 2005; Bintanja et al., 2005; Jansen et al., 2007). The formation of land bridges and gene flow between remote islands at specific time periods during these ice ages, such as during glacial 
maxima, could be used as calibration points for the divergences of insular lineages. Another way of estimating evolutionary rates is to use rapid population expansion events, which can refer to specific causative historic events, as calibration points (Crandall et al., 2012; Ho et al., 2015; Suzuki et al., 2015; Hoareau et al., 2016). For example, terrestrial animal taxa of temperate origin are believed to have been sensitive to the impact of the ice ages and to have experienced rapid expansion events after the bottlenecks caused by the Quaternary impact of glacial cycles and the subsequent population growth attributable to the rapid recovery of habitats during warm periods (Hewitt, 2004).

The murine rodents, which include more than 500 species and a general trend toward broad distribution, even on small islands, offer opportunities for collecting a series of calibrators on certain time scales, thereby facilitating the calculation of time-dependent evolutionary rates. The latter could, in turn, contribute significantly to phylogenetic inference within the species group, including for rats and mice. Among murine rodents, Eurasian wood mice (genus Apodemus) would be ideal subjects. There have been a number of phylogeographic studies on Apodemus species, and these have shown that their spatial genetic architectures have been structured without anthropological influence (Suzuki et al., 2004; Tomozawa and Suzuki, 2008; Tomozawa et al., 2010, 2014; but see Herman et al., 2016) and that their evolution has been spurred by climatic changes and habitat topography (Hsu et al., 2001; Michaux et al., 2004, 2005; Herman et al., 2016).

Two species of Apodemus are endemic to the Japanese Islands. The large wood mouse $A$. specious is the most common rodent in Japan, and as such inhabits small remote peripheral islands, such as Sado Island, Izu Islands, Tsushima Islands and Satsunan Islands, which are currently separated from one another and from the four main islands of Hokkaido, Honshu, Shikoku and Kyushu by deep sea (e.g., > 120 m) (Tada et al., 1999; Tomozawa et al., 2010, 2014). Its dispersal events are thought to have been associated with glacial 100,000-year cycles (Tomozawa and Suzuki, 2008; Tomozawa et al., 2010, 2014; Suzuki et al., 2015) and may thus be useful as calibrators for assessing evolutionary rates.

In a previous study (Suzuki et al., 2015), we focused on sequence variation in the Cytb sequences (1140 bp) of two Apodemus species, the small ( $A$. argenteus) and large $(A$. speciosus) wood mouse. We found strong signals of sudden expansion in the two species from the populations on Hokkaido, the northernmost main island, and the population of $A$. speciosus on the remaining three main islands of Honshu, Shikoku, and Kyushu. Taking into account pollen fossil records from Quercus trees (Igarashi and Oba, 2006; Igarashi, 2010), whose acorns are valuable food resources for wood mice (Saitoh et al., 2008), we ascribed the expansion events to the impact of Quaternary glacial maxima. The emerging estimates illustrate the apparent time dependence of the evolutionary rates obtained using mtDNA markers. Due to a lack of specimens, in that previous study (Suzuki et al., 2015) we failed to clarify the genetic structure of populations of the small Japanese wood mouse $A$. argenteus found on the three main islands.

In the present study, we aimed to produce molecular rate curves by seeking potential calibrators, considering both the intermittent island-island connections and Quaternary glacial climate fluctuations. First, we analyzed Cytb sequence variation in the larger Japanese wood mouse $A$. speciosus from the peripheral islands. Second, we addressed the population expansion events reflected in the Cytb sequences of $A$. argenteus. Our efforts to seek multiple calibrations using both between-island and expansionbased methods should provide useful information on the time-dependent evolutionary rates of mtDNA markers in murine rodents and enable the development of methods for drawing the evolutionary rate curve for a given common terrestrial animal.

\section{MATERIALS AND METHODS}

\section{Sample collection}

The Cytb sequences (1140 bp) of $134 \mathrm{~A}$. argenteus individuals (58 localities; Fig. 1A, Supplementary Table 1) were used. The sequences of $15 A$. argenteus individuals were newly determined in this study; the remainder were those used in previous studies (Serizawa et al., 2000; Suzuki et al., 2004, 2015). The Cytb sequences of $A$. speciosus used in this study (90 individuals) were obtained from databases (e.g., Suzuki et al., 2015), with special emphasis on Sado (Tomozawa et al., 2010) and Izu Islands (Tomozawa et al., 2014). Newly obtained individuals were captured with permission from respective prefectural governments to use them only for academic research. In this work, we followed the guidelines provided by the Mammal Society of Japan. DNA was extracted using the standard phenol-chloroform extraction method (Sambrook and Russell, 2001).

\section{Sequencing analysis}

Sequence determination was performed for Cytb (1140 bp) following a previously described method (Suzuki et al., 2015). The thermal cycling parameters for polymerase chain reaction (PCR) were as follows: $96^{\circ} \mathrm{C}$ for $10 \mathrm{~min}$ and 30 cycles of $96^{\circ} \mathrm{C}$ for $30 \mathrm{~s}$, $50^{\circ} \mathrm{C}$ for $60 \mathrm{~s}$, and $60^{\circ} \mathrm{C}$ for $30 \mathrm{~s}$. PCR products were sequenced using the PRISM Ready Reaction DyeDeoxy Terminator Cycle Sequencing Kit (Applied Biosystems, Foster City, CA, USA) and the ABI3130 automated sequencer (Applied Biosystems). Nucleotide sequences reported in the present study have been deposited in the DDBJ, EMBL, and GenBank nucleotide sequence databases under accession numbers LC136971-LC136984.

\section{Phylogenetic analysis}

Phylogenetic trees for the mtDNA sequences were constructed by the neighbor-joining ( $\mathrm{NJ}$ ) and maximum likelihood (ML) methods in MEGA5 (Tamura et al., 2011) using the evolutionary model Kimura-2-parameter (Kimura, 1980) and the Kishino-HasegawaYano model (Kishino et al., 1985) selected by MEGA5, respectively. The evolutionary rates in Cytb (1140 bp) datasets of the genetic distances $(d)$ for island-island interactions were calculated using the formula $d=2 T \mu$, where $T$ is the time since expansion in years and $\mu$ is the evolutionary rate per site per years. Genetic distances were computed in MEGA5 using a variety of methods, including the Tamura and Nei (1993) distance. Standard error estimates were obtained by bootstrapping (1,000 replicates). We considered $p$-distances (proportion of uncorrected nucleotide differences) to compare them with those that appeared in the expansion-based analysis.

\section{Estimating genetic distances and evolutionary rates}

To detect rapid expansion, we performed mismatch distribution analyses and neutrality tests of Tajima's $D$ (1989) and Fu's $F_{S}$ (1997) using ARLEQUIN ver. 3.5. The expected distribution was simulated 
A
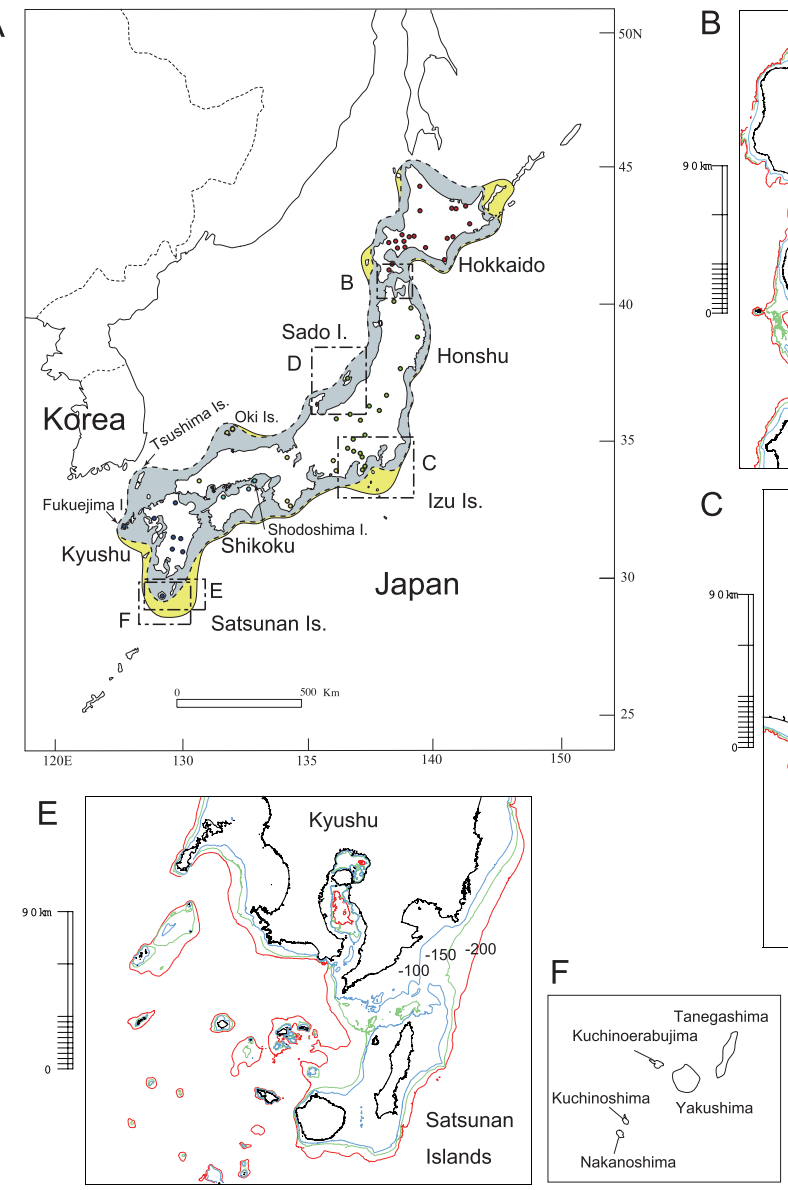

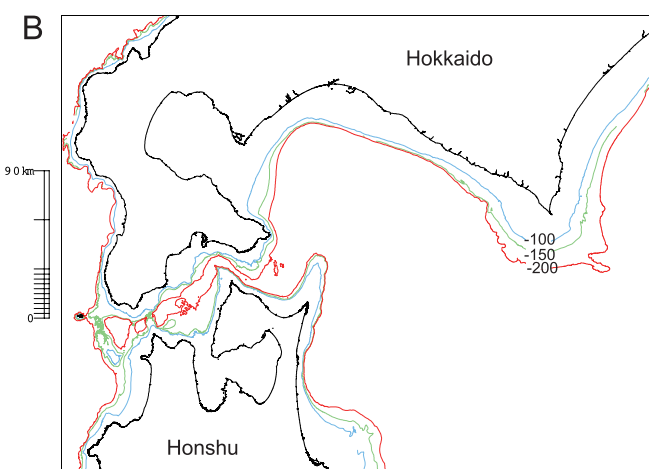

C
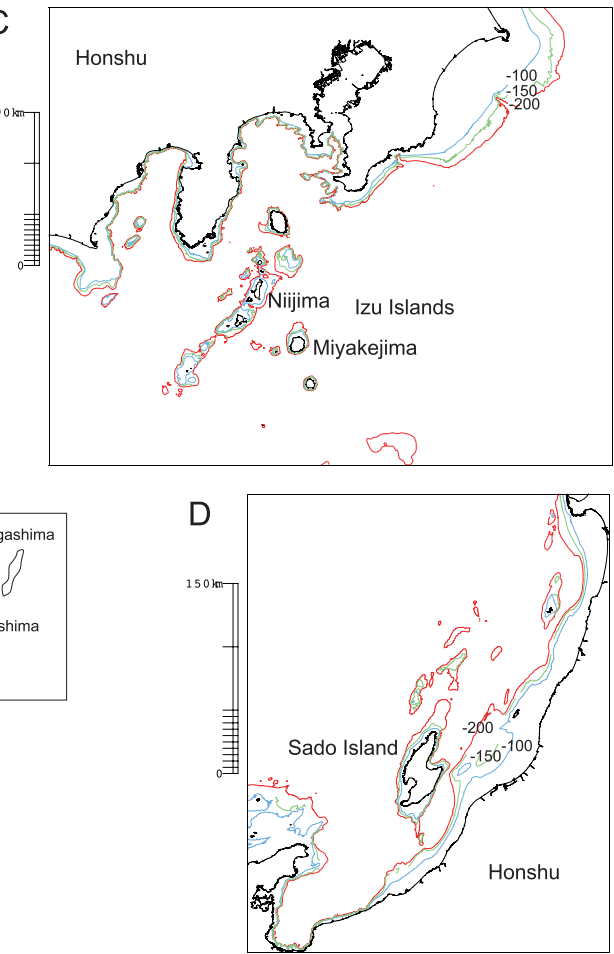

Fig. 1. Locations of the central main Japanese islands of Honshu, Shikoku, and Kyushu (A) and the peripheral islands of Hokkaido (B), Izu (C), Sado (D), and Satsunan (E, F). Rough distribution ranges of Apodemus argenteus and A. speciosus are indicated with dotted and solid lines, respectively (A). Lines indicate current sea depths of 100, 150, and 200 m (Japan Hydrographic Association) (B-E).
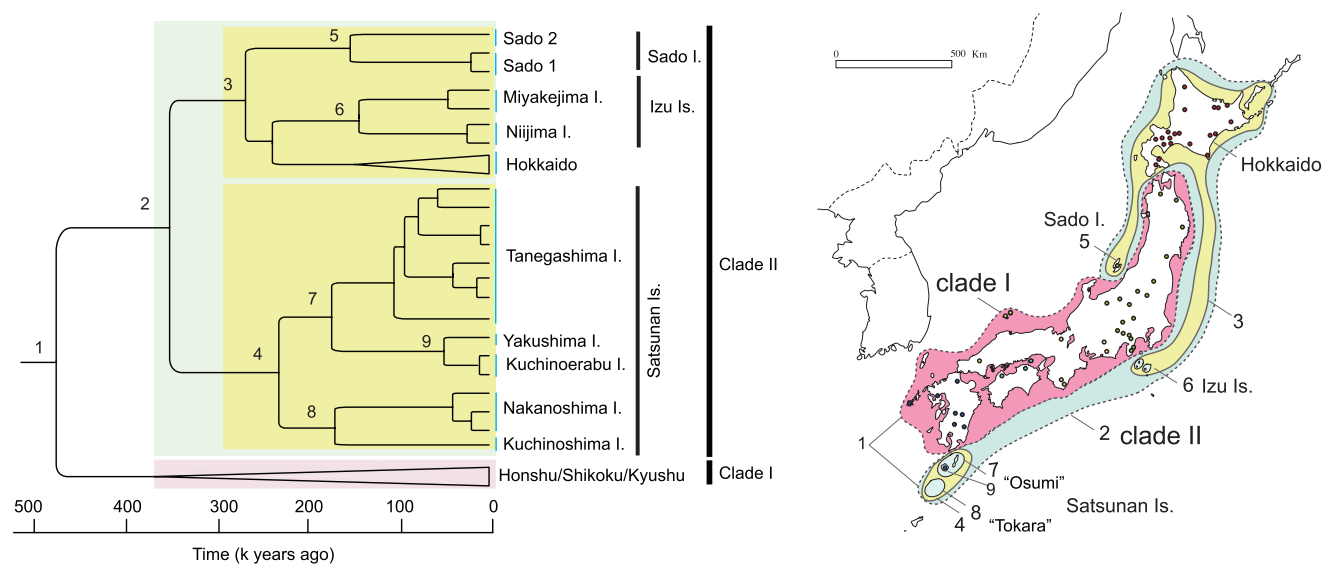

Fig. 2. A Bayesian phylogenetic tree based on mitochondrial cytochrome $b$ sequences (1140 bp) of Apodemus speciosus (Suzuki et al., 2015), showing the geographical structure of central (Honshu, Shikoku, Kyushu) and peripheral island blocks (Sado, Hokkaido, Izu, and Satsunan Islands) (A). Numbers (1-9) of nodes indicate haplotype groups addressed in this study. A map of the Japanese Islands, showing the geographic distribution of the haplotype groups (B). 
Table 1. Estimation of the evolutionary rates $(\mu)$ of cytochrome $b$ based on biogeographic calibrations in large Japanese wood mice Apodemus speciosus.

\begin{tabular}{|c|c|c|c|c|c|c|c|c|c|}
\hline \multirow[t]{2}{*}{ Node } & \multicolumn{2}{|c|}{ Lineages compared } & \multirow{2}{*}{$\begin{array}{l}\text { No. of nucleotide } \\
\text { substitutions }\end{array}$} & \multicolumn{2}{|c|}{ Tamura-Nei ( $p$-distance) } & \multicolumn{2}{|c|}{$\begin{array}{l}\text { Dispersal-based } \\
\text { calibration }\end{array}$} & \multicolumn{2}{|c|}{$\begin{array}{c}\text { Expansion-based } \\
\text { calibration }\end{array}$} \\
\hline & Lineage 1 & Lineage 2 & & Mean & $S D$ & $T$ & $\mu$ & $T$ & $\mu$ \\
\hline \multirow[t]{2}{*}{1} & Clade I & Clade II & 27.1 & 0.02567 & 0.004 & 440 & 0.029 & 425 & 0.030 \\
\hline & & & & $(0.0243)$ & $(0.00347)$ & & $(0.028)$ & & $(0.029)$ \\
\hline \multirow[t]{2}{*}{2} & Satsunan Islands & Sado/lzu/Hokkaido & 20.9 & 0.01904 & 0.00304 & 350 & 0.027 & 340 & 0.028 \\
\hline & & & & $(0.0183)$ & $(0.00287)$ & & $(0.026)$ & & $(0.027)$ \\
\hline \multirow[t]{2}{*}{3} & Sado & Izu & 16.1 & 0.0142 & 0.00298 & 250 & 0.028 & 240 & 0.030 \\
\hline & & & & $(0.0138)$ & $(0.0028)$ & & $(0.028)$ & & $(0.029)$ \\
\hline \multirow[t]{2}{*}{4} & Nakanoshima & Kuchinoshima & 10.5 & 0.00937 & 0.00268 & 140 & 0.034 & 135 & 0.035 \\
\hline & & & & $(0.00921)$ & $(0.00258)$ & & $(0.033)$ & & $(0.034)$ \\
\hline \multirow[t]{2}{*}{5} & Sado 1 & Sado 2 & 11 & 0.01 & 0.00283 & 140 & 0.036 & 135 & 0.037 \\
\hline & & & & $(0.00987)$ & $(0.00269)$ & & $(0.035)$ & & $(0.037)$ \\
\hline \multirow[t]{2}{*}{6} & Miyakejima & Niijima/Shikinejima & 9 & 0.00765 & 0.00218 & 140 & 0.027 & 135 & 0.028 \\
\hline & & & & $(0.00754)$ & $(0.00211)$ & & $(0.027)$ & & $(0.028)$ \\
\hline \multirow[t]{2}{*}{7} & Tanegashima & Yakushima/ & 11.3 & 0.0101 & 0.00283 & 140 & 0.036 & 135 & 0.037 \\
\hline & & Kuchinoerabujima & & $(0.00994)$ & $(0.00273)$ & & $(0.036)$ & & $(0.037)$ \\
\hline \multirow[t]{2}{*}{8} & "Osumi" & “Tokara” & 14 & 0.01304 & 0.0025 & 250 & 0.026 & 245 & 0.027 \\
\hline & & & & $(0.01267)$ & $(0.00236)$ & & $(0.025)$ & & $(0.026)$ \\
\hline \multirow[t]{2}{*}{9} & Yakushima & Kuchinoerabujima & 2.5 & 0.00221 & 0.00134 & 20 & 0.055 & 15 & 0.074 \\
\hline & & & & $(0.00219)$ & $(0.00132)$ & & $(0.055)$ & & $(0.073)$ \\
\hline
\end{tabular}

Genetic distances and standard deviations (SDs) were calculated with substitution models using provided by MEGA5 (Tamura et al., 2011 ). Calibrations were set as the mid-points of the glacial maxima and the initiation time of the interglacial warm periods in the dispersal- and expansion-based calibrations (x 1000 years ago), respectively. Evolutionary rates (substitutions/site/million years) were estimated using the formula $d=2 T \mu$, where $T$ is the time since expansion in years. Estimates obtained with $p$-distances are shown in parentheses.

Codes for nodes are as shown in Fig. 2.

under the sudden expansion model by mismatch distribution analysis (Rogers and Harpending, 1992; Schneider and Excoffier, 1999; Excoffier, 2004) in which the validity of the model was tested using a parametric bootstrap approach with 1000 replicates. In this method, for each replicate, the sum of squared deviation (SSD) between the observed distribution and the expected distribution was compared with the SSD between the simulated distribution and expected distribution. The raggedness index ( $r$; Harpending, 1994) was used as a test statistic for the estimated sudden expansion model.

The expansion parameter tau $(\tau)$ was estimated for Cytb (1140 bp) datasets using ARLEQUIN in clusters showing signs of sudden demographic expansion. A 95\% confidence interval $(\mathrm{Cl})$ around the estimated $\tau$ parameter was obtained using the bootstrap approach. The evolutionary rates of Cytb sequences of rapid expansion events were estimated using the formula $t=\tau / 2 u$, where $t$ is the time since expansion in generations and $u$ is the cumulative evolutionary rate per generation for the entire sequence (Rogers and Harpending, 1992; Rogers, 1995). Here, $u=\mu k g$, where $k$ is the sequence length, and $g$ is the generation time in years. Evolutionary rate ( $\mu$; substitutions/site/years) can thus be estimated using the formula $\mu=\tau / 2 T k$, where $T$ is the time since expansion in years (i.e. $T=t g$ ).

\section{RESULTS}

\section{Evolutionary rate estimation using insular Cytb groups in A. speciosus}

We compared the Cytb sequences of $A$. speciosus, focusing on differences in mtDNA haplotypes among mice found on different Japanese islands, namely, the three cen- tral main islands of Honshu, Shikoku, and Kyushu, and peripheral islands, including Sado, Hokkaido, Izu, and Satsunan, which are separated from the central islands by deep straits (> $120 \mathrm{~m}$; Fig. 1). In the tree generated by BEAST (Drummond and Rambaut, 2007) in our previous study (Suzuki et al., 2015), haplotypes from the same islands formed island-specific clusters (Fig. 2A). The insular lineages formed connections with each other with strong geographic affinity (Fig. 2B), as we previously reported (Suzuki et al., 2004; Tomozawa and Suzuki, 2008; Suzuki et al., 2015). We calculated the genetic distances of nine pairs of haplotype groups (Nodes 1-9 in Fig. 2), with various substitution models provided by MEGA5. The values given by different models differed slightly, but were more or less similar (e.g., Tamura and Nei regarding distance; Table 1). It appeared that the levels of divergence ( $p$-distance) could be categorized into five groups: 1) $0.0022,2) 0.008-0.010,3)$ $0.012-0.014,4) 0.018$, and 5) 0.024 (Table 1), which differed from one another by an approximately constant value of around 0.006 . Assuming that the divergence patterns are a consequence of intermittent dispersal and vicariant events at glacial maxima with a 100,000-year interval (Fig. 3A), we plotted the five groups of genetic distances on the last five glacial maxima of $20,000,140,000,250,000,350,000$, and 440,000 years ago, yielding in a linear regression pattern described by the equation $d=0.0049 T+0.17\left(R^{2}=0.97\right)$, where $T$ is time (in thousands of years) (Fig. 3B). We then calculated the evolutionary rates using the formula $\mu=d / 2 T$ 
A

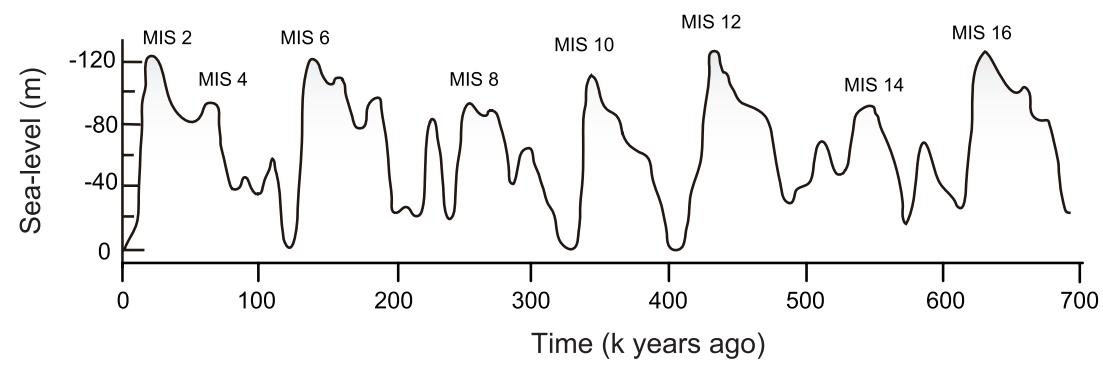

B

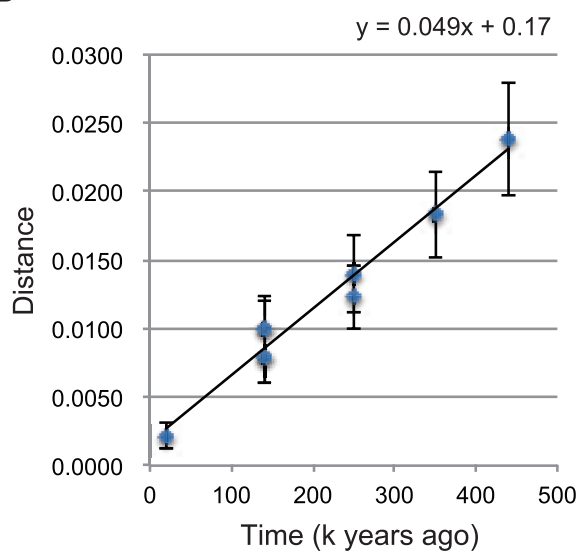

D

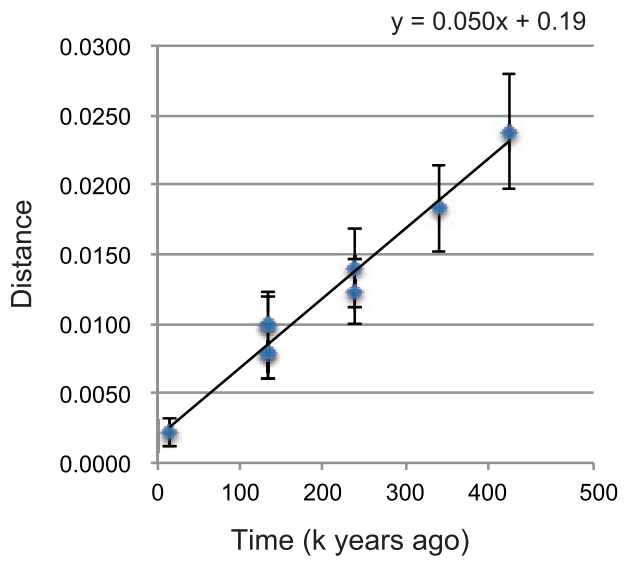

C

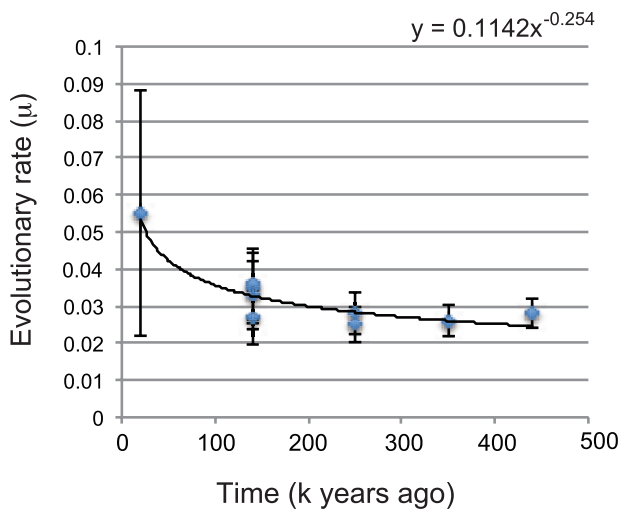

$\mathrm{E}$

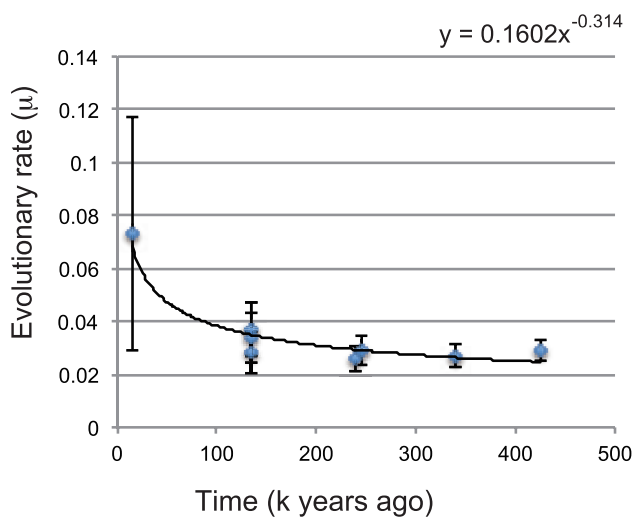

Fig. 3. (A) Sea level changes during the last 700,000 years (Bintanja et al., 2005). The $p$-distances for the divergences of insular lineages of Apodemus speciosus (Table 1) are plotted under the assumption that the divergences were associated with either the appearance and disappearance of land-bridge-like structures for a limited time during the glacial maxima (B) (dispersal-based calibration) or a rapid growth of population size at the beginning of warming periods after the glacial maxima (C) (expansion-based calibration). The evolutionary rates of cytochrome $b$ in the Japanese Apodemus species computed from the dispersal-based (D) and expansion-based (E) calibrations are plotted (see Table 1 for details).

Aiewsakun and Katzourakis, 2016).

Assessment of expansion associated Cytb groups in $A$. argenteus

We constructed NJ and ML trees based on the Cytb sequences of $A$. argenteus, yielding similar patterns in major lineages that we have addressed here (Fig. 4). We observed a number of geographically assigned clusters of haplotypes. First, we denoted two major lineages (clades I and II; Suzuki et al., 2004, 2015), the latter of which was confined to the western part of the Japanese islands, while the former was recovered from the entire Japanese island region. In clade I, four distinct sublineages (la-ld) were detected, among which sublineage la was further divided into three subclades, la-1-la-3, supported by moderate bootstrap values of $75-78 \%$, 63-67\%, and 89-92\%, respectively. Lineage Ib comprised haplotypes from the Oki Islands, Yakushima Island, and Honshu. The remaining lineages, Ic $(n=2)$ and Id ( $n=1$ ), had limited numbers of members; Id was represented by a haplotype from Fukuejima Island, Kyushu. In clade II, two subclades were found (Ila, IIb). Notably, one of them, Ilb $(n=8)$, was formed by haplotypes only from Shikoku and Kyushu, while lla was formed by those from the western half of the Japanese islands.

We estimated genetic and plotted them against time (Fig. 3C). A trend toward a rapid decrease from 0.055 to $0.029-0.036$ substitutions/site/ my ( $p$-distance rate) over the time period from 20,000 to 140,000 years ago was seen, followed by a gradual decrease from 0.036 to 0.027 over the time period from 140,000 to 440,000 years ago; this is described by the equation $\mu=$ $0.1142 T^{-0.254},\left(R^{2}=0.85\right)$, which involves a trend toward a power-law decay that matches well with previous studies on the time-dependent evolutionary rates (Ho et al., 2005; distances $(d)$ among the clusters seen in the Cytb tree of $A$. argenteus and found four different levels of $p$-distance values: 1) 0.03 for the two major clades, 2) 0.018 for clades Ila and IIb, 3) 0.015 for clades la-Id, and 4) 0.010 for clades la-1 and la-2 (plus la-3) (Table 2).

We further addressed lineage expansion events in $A$. argenteus, performing Tajima's D, Fu's Fs, and mismatch distribution analyses on possible haplotype groups seen in the Cytb tree. We confirmed considerable signals of rapid 
Table 2. Estimation of evolutionary rates $(\mu)$ of the cytochrome $b$ gene (1140 bp) with calibrations of population expansions.

\begin{tabular}{|c|c|c|c|c|c|c|c|c|c|}
\hline $\begin{array}{l}\text { Species and haplotype group } \\
\text { (main range) }\end{array}$ & $\mathrm{N}$ & Tajima's $D$ & Fu's Fs & SSD & $\tau(\mathrm{Cl})$ & $d$ in \% $(\mathrm{Cl})$ & $\begin{array}{l}\text { Expansion } \\
\text { time }(\mathrm{Cl})\end{array}$ & Calibration & $\mu(\mathrm{Cl})$ \\
\hline \multicolumn{10}{|l|}{ Apodemus argenteus } \\
\hline la-1_group A (Hokkaido) & 72 & $-2.67^{* *}$ & $-26.89^{* *}$ & 0.0023 & $\begin{array}{c}2.55 \\
(1.98-3.07)\end{array}$ & $\begin{array}{c}0.22 \\
(0.17-0.27)\end{array}$ & $\begin{array}{c}11.2 \\
(0.8-20.3)\end{array}$ & 10 & $\begin{array}{c}0.110 \\
(0.085-0.135)\end{array}$ \\
\hline $\begin{array}{l}\text { la-1_group B } \\
\text { (eastern Honshu) }\end{array}$ & 21 & $-1.98^{\star \star}$ & $-7.46^{\star \star}$ & 0.0054 & $\begin{array}{c}3.89 \\
(2.51-5.37)\end{array}$ & $\begin{array}{c}0.34 \\
(0.22-0.47)\end{array}$ & $\begin{array}{c}34.9 \\
(10.2-61.4)\end{array}$ & 15 & $\begin{array}{c}0.113 \\
(0.073-0.157)\end{array}$ \\
\hline $\begin{array}{l}\text { la-1_group C } \\
\text { (Honshu, Shikoku, Kyushu) }\end{array}$ & 17 & $-158^{*}$ & $-9.61^{\star *}$ & 0.0041 & $\begin{array}{c}5.70 \\
(3.60-9.079)\end{array}$ & $\begin{array}{c}0.50 \\
(0.32-0.80)\end{array}$ & $\begin{array}{c}67.3 \\
(29.8-127.8)\end{array}$ & 53 & $\begin{array}{c}0.047 \\
(0.030-0.075)\end{array}$ \\
\hline la-2 (Honshu) & 6 & -1.19 & $-2.18^{*}$ & 0.020 & $\begin{array}{c}5.67 \\
(3.59-7.99)\end{array}$ & $\begin{array}{c}0.50 \\
(0.31-0.70)\end{array}$ & $\begin{array}{c}66.8 \\
(29.6-108.3)\end{array}$ & 53 & $\begin{array}{c}0.047 \\
(0.029-0.066)\end{array}$ \\
\hline Ib (Oki, Yakushima, western Honshu) & 12 & -1.59 & $-5.76^{\star \star}$ & 0.012 & $\begin{array}{c}8.09 \\
(4.71-10.98)\end{array}$ & $\begin{array}{c}0.71 \\
(0.41-0.96)\end{array}$ & $\begin{array}{c}110.1 \\
(49.6-161.9)\end{array}$ & 115 & $\begin{array}{c}0.031 \\
(0.018-0.420)\end{array}$ \\
\hline Ilb (Shikoku, Kyushu) & 8 & -1.4 & $-2.97^{\star}$ & 0.0059 & $\begin{array}{c}7.75 \\
(4.73-10.04)\end{array}$ & $\begin{array}{c}0.68 \\
(0.41-0.88)\end{array}$ & $\begin{array}{c}104.0 \\
(50.0-145.0)\end{array}$ & 115 & $\begin{array}{c}0.030 \\
(0.018-0.038)\end{array}$ \\
\hline \multicolumn{10}{|l|}{ Apodemus speciosus } \\
\hline Ila_ex_Ila-1 (Hokkaido) & 37 & $-1.827^{*}$ & $-10.03^{\star *}$ & 0.0019 & $\begin{array}{c}2.70 \\
(0.98-3.93)\end{array}$ & $\begin{array}{c}0.24 \\
(0.09-0.34)\end{array}$ & $\begin{array}{c}13.6 \\
(0-35.7)\end{array}$ & 10 & $\begin{array}{c}0.120 \\
(0.045-0.170)\end{array}$ \\
\hline I (Honshu, Shikoku, Kyushu) & 34 & $-1.746^{*}$ & $-18.84^{\star *}$ & 0.0037 & $\begin{array}{c}9.21 \\
(5.84-11.87)\end{array}$ & $\begin{array}{c}0.81 \\
(0.51-1.04)\end{array}$ & $\begin{array}{c}130.2 \\
(69.9-175.3)\end{array}$ & 130 & $\begin{array}{c}0.031 \\
(0.020-0.040)\end{array}$ \\
\hline
\end{tabular}

Tajimas' $D$, Fu's $F s$, SSD, and $\tau(\mathrm{Cl}$, confidence interval) values were obtained using ARLEQUIN ver 3.5 (Excoffier and Lischer, 2010$)$. $P<$ $0.05,{ }^{*} P<0.01$.

Genetic distances $(d)$ were calculated using the formula $d=\tau / k(k=1140)$.

Expansion times ( $T$ in 1000 years ago) were calculated with help of the formula obtained from the plot shown in Fig. 3B $(d=0.0049 T+0.17)$. Calibrations (x 1000 years ago) were set in consideration of the vegetative changes during the last ice ages (Igarashi and Oba, 2006; Yamamoto et al., 2014). Evolutionary rates ( $\mu$, substitutions/site/million years) were estimated using the formula $d=2 T \mu$.

See Suzuki et al. (2015) for the haplotype groups of $A$. speciosus.

expansion events in several specific groups of Cytb haplotypes, including that of Hokkaido (la-1_group A in Fig. 4B), which has already been identified (Suzuki et al., 2015). The five other possible haplotype groups with considerable expansion signals were la-1_group B, la-1_group C, la-2, Ib, and IIb (Fig. 4B, Table 2). The values of $\tau$ for these haplotype groups ranged from 2.6 to 8.1 (Table 2), of which the lowest was for the group from Hokkaido (la-1_group A) and the highest for the group la-2 comprising haplotypes from the Oki Islands, Yakushima Island, Shodoshima Island, Shikoku, and several localities in the western part of Honshu.

\section{DISCUSSION}

\section{Calibrations of dispersals among remote islands at gla- cial maxima}

In this study, we sought to determine the time-dependent evolutionary rate $(\mu)$ of the mtDNA Cytb sequences of wood mice over the past one-half million years. To do so, we investigated the mtDNA divergence patterns in the insular populations of $A$. speciosus found on the central island block (Honshu, Shikoku, and Kyushu) and four peripheral blocks (Sado, Hokkaido, the Izu Islands, and the Nansei Islands). Since these peripheral remote islands are currently separated by deep sea (e.g., $120 \mathrm{~m}$ for Tsugaru Strait and > $200 \mathrm{~m}$ for straits separating the Izu Islands) (Fig. 1) and the sea depth decreased to less than 100 m only during the glacial maxima (Bintanja et al., 2005; Jansen et al., 2007), it is plausible that the phylogeographic patterns were formed by the appearance and disappearance of land-bridge-like structures at the glacial maxima with 100,000-year intervals during the Quaternary ice ages. This is consistent with a previous notion that originated from BEAST (Drummond and Rambaut, 2007) analysis with an evolutionary rate of 0.03 substitutions/site/my, which was obtained by calibration of a rapid expansion event around 130,000 years ago (Suzuki et al., 2015), showing a trend in divergence patterns of the insular lineages of around 100,000-year intervals.

Assuming that the Cytb lineage divergences have been shaped by migration between islands at the glacial maxima with 100,000-year intervals (Jansen et al., 2007), we were able to specify the time periods for the five divergent groups of $A$. speciosus (Table 1). The shallowest two may be associated with the glacial maxima 20,000 and 140,000 years ago, accounting for the genetic distances being comparable to those observed in the rapid expansion events of Japanese wood mice (Suzuki et al., 2015). The remaining three groups may then be associated with the older glacial maxima $250,000,350,000$, and 440,000 years ago. The plot illustrates a trend of the time-dependent evolutionary rates and gives us a rationale for using $0.036-0.027$ substitutions/site/ my as the evolutionary rate when assessing the divergence time using Cytb datasets from wood mice, covering the time period from 140,000 to 440,000 years ago (Fig. 3C).

\section{Estimation of evolutionary rates using calibrations of historical rapid expansion events}

In addition to the calibrations of the dispersal events among the remote islands at the glacial maxima, other worthwhile calibrations are those accounting for rapid expansions promoted by rapid cooling and subsequent rapid 


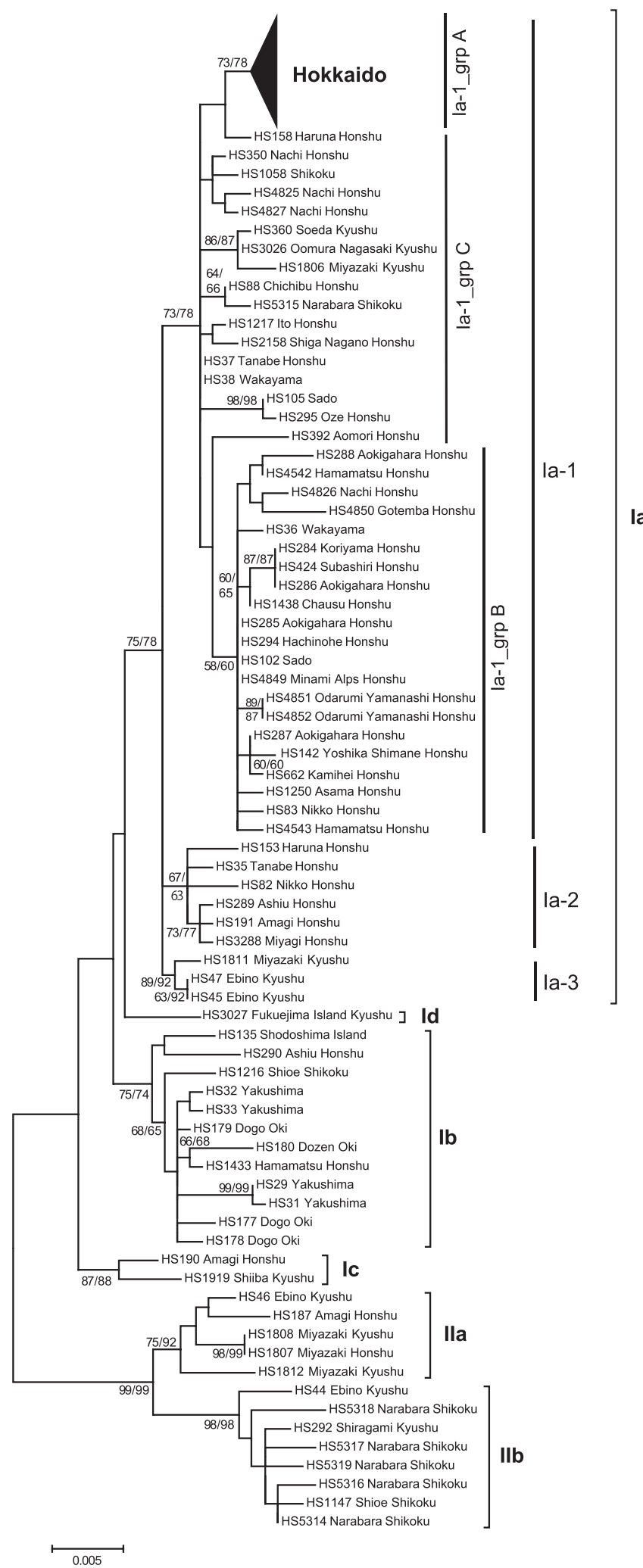

Fig. 4. An unrooted maximum likelihood tree for Apodemus argenteus based on mitochondrial DNA cytochrome $b$ sequences. Only high bootstrap values are shown at the branches (1000 replicates, > 60\%). Numbers at nodes indicate bootstrap values of maximum-likelihood and neighbor-joining methods (1000 replicates, $>60 \%$ ). The taxon names correspond to those in Supplementary Table S1. warming (Suzuki et al., 2015). The survey of rapid expansion reflected in the Cytb sequences (1140 bp) of $A$. argenteus from Honshu/Shikoku/Kyushu showed several expansion events, in which $\tau$ values varied substantially, ranging from 3.9 to 8.1 (Table 2). In our view, these $\tau$ values can be categorized into three groups: 3.9 (la-1_group B), 5.6-5.7 (la-1_ group C, la-2), and 7.8-8.1 (lb, Ilb; Table 2). Because the two distinct $\tau$ levels, 2.4-2.7 in Hokkaido and 9.2 in the central main islands, have been assigned to the rapid warming periods 10,000 and 130,000 years ago, respectively, in our previous study (Suzuki et al., 2015), the three newly detected ranges of $\tau$ values can be allocated to geological events that occurred during the period 10,000-130,000 years ago.

The question is how to interpret the three expansion events based on available specific paleontological evidence. The past 130,000 years is the most well-known and important period to have affected population dynamics in a variety of organisms, including broadleaf and coniferous trees. Considerable vegetative changes during the last ice ages have been well demonstrated using various lines of evidence. For example, in a lake in central Honshu, Japan, an index of the contributions of angiosperms versus gymnosperms (S/V ratio; Hedges and Mann, 1979) showed peaks during interglacial periods (e.g., mid-MIS 5 e, the MIS $5 d / 5 c$ boundary, MIS 5a, and early MIS 3) (Yamamoto et al., 2014). Taking into account the vegetative fluctuations, including those in the past 130,000 years, one can specify the five periods that are associated with high values of the pollen temperature index the ratio of temperate taxa (e.g., Quercus) to all taxa (temperate + subalpine taxa) (Kanauchi et al., 2007); 129,000-119,000, 115,000-100,000, 82,000-76,000, $53,000-49,000$, and $15,000-0$ years ago (Fig. 5A; Igarashi and Oba, 2006). It is reasonable to think that the $\tau$ values reflect expansion events that started during any of the four warming periods, presumably 15,000,53,000, 82,000, and 115,000 years ago. We calculated expansion times for each of the $\tau$ values after transforming them into genetic distances $(d=\tau / k ; k=1,140)$ (Table 2) with the aid of the equation obtained from the plot of the insular lineage divergences, $d$ (in \%) $=0.0049 T+0.17$ (Fig. 3B). It seems likely that the three levels of $\tau$ values, 3.9, 5.6-5.7, and 7.8-8.1, correspond to the warmer periods that started at around 15,000, 53,000 , and 115,000 years ago, respectively (Table 2). These considerations led us to propose possible plots for the $\tau$ values ( $\tau=0.48 T+2.7, R^{2}=0.97$; Fig. $5 \mathrm{~B}$ ), which can be expressed as a plot for the genetic distances $(d=0.0042$ $T+0.24, R^{2}=0.97$; data not shown). Evolutionary rates (substitutions/site/my) for the calibrations of $15,000,53,000$, and 115,000 years ago were assumed to be $0.114,0.047$, and 0.031 , respectively $\left(\mu=0.0438 T^{-0.557}, R^{2}=0.98\right.$; Fig. $5 C)$. This preliminary theory of evolutionary rates in the time scale of wood mouse evolution should be tested in other species of murine rodents, including mice and rats.

Interestingly, the equations obtained in this study imply that the genetic distance can be characterized as a combination of a portion that correlates with time (0.0043-0.0049 $T$; $T$ in thousands of years) and a constant portion (0.17$0.24)$. From the value of the former portion, one may consider the Cytb evolutionary rate to be $0.021-0.025$ substitutions/site/my (Fig. 5B), which is comparable to previously proposed long-term substitution rates, such as 0.024 substi- 
A

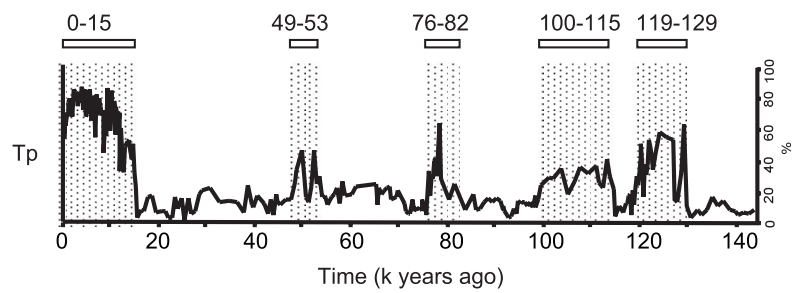

B

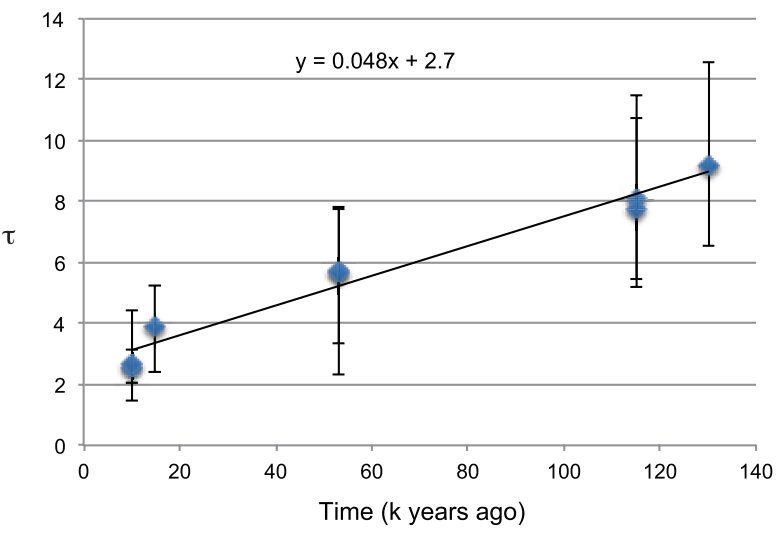

C

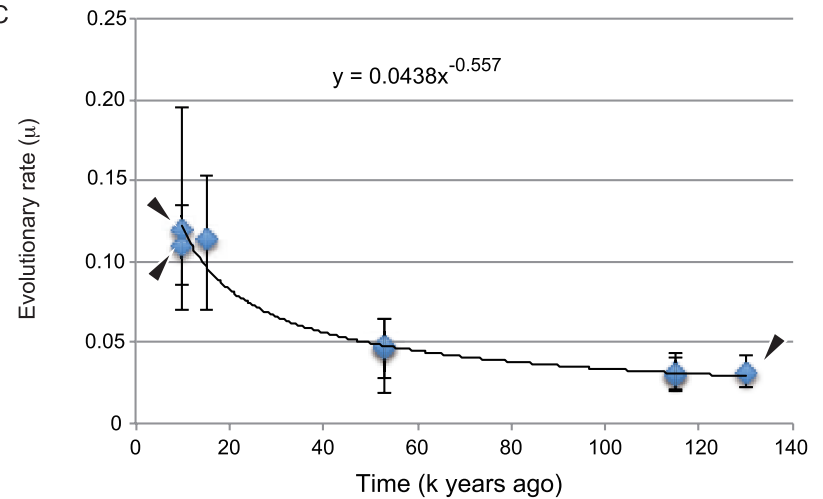

Fig. 5. Inferred climatic changes during 144,000 years based on high-resolution pollen analysis on a core from the northwest Pacific off the coast of central Japan (Igarashi and Oba, 2006) (A). The Tp value (Kanauchi et al., 2007) is the ratio of the pollen abundance of cool-temperate broadleaf trees to the sum of that of cool-temperate broadleaf plants and subarctic conifer trees (defined by Igarashi and Oba, 2006). Five noticeable epochs of sharp increases in temperate tree species are marked (Igarashi and Oba, 2006). (B) $\tau$ values obtained from the cytochrome $b(1140 \mathrm{bp})$ analyses are plotted. The three data points were obtained based on the assumption that the rapid expansion of the mitochondrial DNA haplotype groups in Apodemus argenteus was associated with the specific geological events of rapid cooling and rapid warming 15,000,53,000, and 115,000 years ago (Table 2). Other $\tau$ values from our previous study for 10,000 and 130,000 years ago (arrowheads; Suzuki et al., 2015) are plotted (see Table 2 for details). (C) The evolutionary rates (substitutions/site/million years) of cytochrome $b$ in the Japanese Apodemus species calculated from the resultant plot shown in (B). Those predicted in a previous study (Suzuki et al., 2015) are shown with arrowheads.

tutions/site/my (Suzuki et al., 2003) and $~ 0.026$ substitutions/site/my (Soares et al., 2013), based on paleontological calibration of the rat-mouse split as 12 million years ago. In addition, from the latter portion of the equations, as exempli- fied in a non-zero genetic distance at time 0 in the plots shown in Figs. $3 \mathrm{~B}$ and $5 \mathrm{~B}$, one may assume that this accounts for the time dependence of the evolutionary rates. Although assessing the factors shaping the time-dependency is beyond the scope of this study, the presence of the constant portion (i.e., approximately one substitution per 1000 $\mathrm{bp}$ ) is likely to be explained either by ancestral polymorphism (e.g., Peterson and Masel, 2009) or mildly deleterious mutations (Ho et al., 2011). Such deleterious mutations will be removed over considerable time frames in a similar fashion in both amino-acid coding (Cytb) and non-coding (control) regions (Suzuki et al., 2015).

\section{Drawing predicted time-dependent evolutionary rate curves in Apodemus}

Drawing evolutionary rate curves should significantly improve our understanding of the evolutionary history of a given species. In this study, as discussed above, we present a preliminary concept for the molecular rates of wood mice, using calibrations from the two independent methods of consideration, namely, predicting island-island interactions at 100,000-year intervals (Fig. 3C) and rapid expansion events associated with climatic changes (Fig. 5C). Combining the two constructed curves, it has been shown that the evolutionary rates (per site per my) rapidly decrease from 0.11 through 0.05 to 0.03 over the time course of 10,000 through 60,000 to 130,000 years ago. Standard molecular rate curves are useful tools for estimating the divergence time in a given pair of lineages. We estimated the divergence time for two clades, I and II, of $A$. argenteus, using the newly created molecular rate curve (Fig. $3 C$ ). The $p$-distance for the two clades is 0.030 , and the divergence time was calculated to be 540,000 years ago.

In drawing the curves of the evolutionary rate, we assumed interactions between islands at the glacial maxima of 100,000-year intervals. However, given that population expansions during the warming periods associated with glacial maxima are the most likely drivers of multiple branching in the mtDNA lineages in the wood mice of temperate origin (Tomozawa et al., 2014; Suzuki et al., 2015), assuming that the branching patterns have been shaped by expansion events in the interglacial warm periods immediately after the glacial maxima of 100,000-year intervals, there may be an alternative explanation for the divergence in the data on the remote islands. Setting expansion-based calibration points, namely the initiation times of the interglacial warm periods (Jansen et al., 2007), provides alternative plotting points for the genetic distances between the insular lineages (Fig. 3D) and evolutionary rates (Fig. 3E) for the time span of 130,000 to 430,000 years ago, which are slightly higher than, but similar to, those obtained based on interaction between islands at the glacial maxima (Table 1).

Interestingly, there is an apparent trend in the $\tau$ values in the two Japanese wood mouse species, namely, lower in the north and higher in the south (Table 2). The $\tau$ values of $A$. argenteus exhibit a particularly strong latitudinal trend: 2.6 in Hokkaido, 3.9 in eastern Honshu, 5.7 in Honshu/Shikoku/ Kyushu, and 7.8-8.1 in western Honshu, Shikoku, and Kyushu. This implies that the four cycles of rapid cooling and rapid warming during the last 140,000 years have affected the populations of the lesser wood mouse $A$. argenteus dif- 
ferently in terms of spatial and temporal aspects. In contrast, the larger wood mouse $A$. speciosus is likely to have been affected by the two recent glacial maxima 20,000 and 140,000 years ago in Hokkaido and Honshu/Shikoku/ Kyushu, respectively. It is unclear what factors caused this difference in the two sympatric species, which should be addressed in future studies.

\section{CONCLUSION}

This study proposes evolutionary rates covering the period from 10,000 to 450,000 years ago, with a drastic decrease from 10,000 ( 0.12 substitutions/site/my) to 130,000 years ago ( 0.03 substitutions/site/my), followed by a rather constant rate of approximately 0.027 substitutions/ site/my. Although extensive verification of these values is necessary, this information could have a major impact on phylogenetic and phylogeographic studies, revealing the possible evolutionary rates of mtDNA, based on geological and biogeographical calibrators, not only for wood mice but also for other members of the large taxon of the Murinae subfamily, which includes the genera Rattus and Mus. Finally, we stress that the two wood mouse species endemic to Japan were likely sensitive to the glacial maxima and to the rapid cooling and warming cycle during the last 140,000 years, as is exemplified by a number of species, including black bears (Ohnishi et al., 2009), giant flying squirrels (Oshida et al., 2009), and hares (Nunome et al., 2010). Species found in multiple insular domains on the Japanese islands, which are long from north to south, would be ideal subjects to determine time-dependent evolutionary rates of mtDNA in other organisms using the same approaches as used in this study.

\section{ACKNOWLEDGMENTS}

We would like to thank Yaeko Igarashi, Masaharu Motokawa, Jun J. Sato, and Kimiyuki Tsuchiya for providing valuable comments on an earlier manuscript. This study was supported by grants-in-aid for Scientific Research (C) from the Japan Society for the Promotion of Science (JSPS) to HS (no. 20570078).

\section{COMPETING INTERESTS}

The authors have no competing interests to declare.

\section{AUTHOR CONTRIBUTIONS}

TK, NM, GK, KA and HS participated in the experimental design. TK and HS carried out all computational analyses. TK wrote the first draft of the manuscript. All authors contributed to the final version of the manuscript.

\section{REFERENCES}

Aiewsakun P, Katzourakis A (2015) Endogenous viruses: Connecting recent and ancient viral evolution. Virology 479: 26-37

Bintanja R, van de Wal RSW, Oerlemans J (2005) Modelled atmospheric temperatures and global sea levels over the past million years. Nature 437: 125-128

Crandall ED, Sbrocco EJ, DeBoer TS, Barber PH, Carpenter KE (2012) Expansion dating: calibrating molecular clocks in marine species from expansions onto the Sunda Shelf following the Last Glacial Maximum. Mol Biol Evol 29: 707-719

Drummond AJ, Rambaut A (2007) BEAST: Bayesian evolutionary analysis by sampling trees. BMC Evol Biol 7: 1-8

Excoffier L, Lischer HEL (2010) Arlequin suite ver 35: A new series of programs to perform population genetics analyses under
Linux and Windows. Mol Ecol Res 10: 564-567

Excoffier L (2004) Patterns of DNA sequence diversity and genetic structure after a range expansion: lessons from the infinite island model. Mol Ecol 13: 853-864

Fu XY (1997) Statistical tests of neutrality of mutations against population growth hitchhiking and background selection. Genetics 147: 915-925

Galtier N, Nabholz B, Glemin S, Hurst GD (2009) Mitochondrial DNA as a marker of molecular diversity: a reappraisal. Mol Ecol 18: 4541-4550

Harpending RC (1994) Signature of ancient population growth in a low-resolution mitochondrial DNA mismatch distribution. Human Biol 66: 591-600

Hasegawa M, Kishino H, Yano T (1985) Dating of the human-ape splitting by a molecular clock of mitochondrial DNA. J Mol Evol 22: $160-174$

Hedges JI, Mann DC (1979) The characterization of plant tissues by their lignin oxidation products. Geochim Cosmoch Acta 43: 1803-1807

Herman JS, McDevitt AD, Kawałko A, Jaarola M, Wójcik JM, Searle JB (2014) Land-bridge calibration of molecular clocks and the post-glacial colonization of Scandinavia by the Eurasian field vole Microtus agrestis. PLoS ONE 9: e103949

Herman JS, Jóhannesdóttir F, Jones EP, McDevitt AD, Michaux JR, White TA, et al. (2016) Post-glacial colonization of Europe by the wood mouse, Apodemus sylvaticus: evidence of a northern refugium and dispersal with humans. Biol J Linn Soc (DOI: 10.1111/bij.12882)

Hewitt GM (2004) Genetic consequences of climatic oscillations in the Quaternary. Phil Tran Roy Soc Lond Ser B Biol Sci 359: 183-195

Ho SYW, Larson G (2006) Molecular clocks: when times are a-changin'. Trends Genet 22: 79-83

Ho SYW, Lanfear R, Bromham L, Phillips MJ, Soubrier J, Rodrigo AG, Cooper A (2011) Time-dependent rates of molecular evolution. Mol Ecol 20: 3087-3101

Ho SYW, Tong JK, Foster CSP, Ritchie AM, Lo N, Crisp MD (2015) Biogeographic calibrations for the molecular clock. Biol Lett 11: 20150194

Hoareau TB (2016) Late-glacial demographic expansion motivates a clock overhaul for population genetics. Syst Biol 65: 449-464

Howell N, Howell C, Elson JL (2008) Time dependency of molecular rate estimates for mtDNA: this is not the time for wishful thinking. Heredity 101: 107-108

Hsu FH, Lin FJ, Lin YS (2001) Phylogeographic structure of the Formosan wood mouse Apodemus semotus. Thomas Zool Stud 40: 91-102

Igarashi $Y(2010)$ Vegetation and climate history in Sakhalin and Hokkaido: Migration, rise and fall of plants inferred from pollen records. Quat Res 49: 241-253 (in Japanese)

Igarashi, Y Oba T (2006) Fluctuations in the East Asian monsoon over the last $144 \mathrm{ka}$ in the northwest Pacific based on a highresolution pollen analysis of IMAGES core MD01-2421. Quat Sci Rev 25: 1447-1459

Jansen E, Overpeck J, Briffa K, Duplessy J, Joos F, MassonDelmotte V, et al. (2007) Palaeoclimate. Chapter 6. In "Climate Change 2007: The Physical Science Basis, Contribution of Working Group I to the Fourth Assessment Report of the Intergovernmental Panel on Climate Change", Ed by S Solomon, D Qin, M Manning, Z Chen, M Marquis, KB Averyt, M Tignor, HL Miller. Cambridge University Press Cambridge United Kingdom and New York NY USA

Kanauchi A, Kawai S, Kumon F (2007) Pollen analysis of the boring core obtained from Takanao formation Nagano Prefecture central Japan. Programme and Abstracts No 37: 166-167 Jap Ass Quat Res (in Japanese)

Kimura M (1980) A simple method for estimating evolutionary rates 
of base substitutions through comparative studies of nucleotide sequences. J Mol Evol 16: 111-120

Lambeck K, Esat TM, Potter EK (2002) Links between climate and sea levels for the past three million years. Nature 419: 199-206

Lisiecki LE, Raymo ME (2005) A Pliocene-Pleistocene stack of 57 globally distributed benthic $\delta^{18} \mathrm{O}$ records. Paleoceanography 20: PA1003

Martínková N, Barnett R, Cucchi T, Struchen R, Pascal M, Pascal $M$, et al. (2013) Divergent evolutionary processes associated with colonization of offshore islands. Mol Ecol 22: 5205-5220

Michaux JR, Libois R, Paradis E, Fillippucci MG (2004) Phylogeographic history of the yellow-necked fieldmouse (Apodemus flavicollis) in Europe and in the Near and Middle East. Mol Phylogenet Evol 32: 788-798

Michaux JR, Bellinvia E, Lymberakis P (2005) Taxonomy, evolutionary history and biogeography of the broad-toothed field mouse (Apodemus mystacinus) in the eastern Mediterranean area based on mitochondrial and nuclear genes. Biol J Linn Soc 85: $53-63$

Molak M, Ho SYW (2015) Prolonged decay of molecular rate estimates for metazoan mitochondrial DNA. PeerJ 3: e821

Nunome M, Torii H, Matsuki R, Kinoshita G, Suzuki H (2010) The influence of Pleistocene refugia on the evolutionary history of the Japanese hare, Lepus brachyurus. Zool Sci 27: 469-754

Ohnishi N, Uno R, Ishibashi Y, Tamate HB, Oi T (2009) The influence of climatic oscillations during the Quaternary Era on the genetic structure of Asian black bears in Japan. Heredity 102: 579-589

Oshida T, Masuda R, Ikeda K (2009) Phylogeography of the Japanese giant flying squirrel Petaurista leucogenys (Rodentia: Sciuridae): implication of glacial refugia in an arboreal small mammal in the Japanese Islands. Biol J Linn Soc 98: 47-60

Peterson GI, Masel J (2009) Quantitative prediction of molecular clock and ka/ks at short timescales. Mol Biol Evol 26: 25952603

Rogers AR (1995) Genetic evidence for a Pleistocene population explosion. Evolution 49: 608-615

Rogers AR, Harpending H (1992) Population growth makes waves in the distribution of pairwise genetic differences. Mol Biol Evol 9: $552-569$

Saitoh T, Vik JO, Stenseth NC, Takanishi T, Hayakashi S, Ishida N, et al. (2008) Effects of acorn abundance on density dependence in a Japanese wood mouse (Apodemus speciosus) population. Popul Ecol 50: 159-167

Sambrook J, Russell DW (2001) Molecular Cloning: A Laboratory Manual 3rd ed. Cold Spring Harbor Laboratory Press, Cold Spring Harbor, New York

Schneider S, Excoffier L (1999) Estimation of demographic parameters from the distribution of pairwise differences when the mutation rates vary among sites: application to human mitochondrial DNA. Genetics 152: 1079-1089

Serizawa K, Suzuki H, Tsuchiya K (2000) A phylogenetic view on species radiation in Apodemus inferred from variation of nuclear and mitochondrial genes. Biochem Genet 38: 27-40

Soares P, Abrantes D, Rito T, Thomson N, Radivojac P, Li B, et al. (2013) Evaluating purifying selection in the mitochondrial DNA of various mammalian species. PLoS ONE 8: e58993

Suzuki H, Sato JJ, Tsuchiya K, Luo J, Zhang Y-P, Wang Y-X, Jiang $X-L$ (2003) Molecular phylogeny of wood mice (Apodemus Muridae) in East Asia. Biol J Linn Soc 80: 469-481

Suzuki H, Yasuda SP, Sakaizumi M, Wakana S, Motokawa M, Tsuchiya K (2004) Differential geographic patterns of mitochondrial DNA variation in two sympatric species of Japanese wood mice Apodemus speciosus and A. argenteus. Genes Genet Syst 79: 165-176

Suzuki H, Nunome M, Kinoshita G, Aplin KP, Vogel P, Kryukov AP, et al. (2013) Evolutionary and dispersal history of Eurasian house mice Mus musculus clarified by more extensive geographic sampling of mitochondrial DNA. Heredity 111: 375-390

Suzuki Y, Tomozawa M, Koizumi Y, Tsuchiya K, Suzuki H (2015) Estimating the molecular evolutionary rates of mitochondrial genes referring to Quaternary Ice Age events with inferred population expansions and dispersals in Japanese Apodemus. BMC Evol Biol 15: 187

Tada R, Irino T, Koizumi I (1999) Land-ocean linkages over orbital and millennial timescales recorded in late Quaternary sediments of the Japan Sea. Paleoceanography 14: 236-247

Tajima F (1989) Statistical method for testing the neutral mutation hypothesis by DNA polymorphism. Genetics 123: 585-595

Tamura K, Nei M (1993). Estimation of the number of nucleotide substitutions in the control region of mitochondrial DNA in humans and chimpanzees. Mol Biol Evol 10: 512-526

Tamura K, Peterson D, Peterson N, Stecher G, Nei M, Kumar S (2011) MEGA5: molecular evolutionary genetics analysis using maximum likelihood, evolutionary distance, and maximum parsimony methods. Mol Biol Evol 28: 2731-2739

Tomozawa M, Suzuki H (2008) A trend of central versus peripheral structuring in mitochondrial and nuclear gene sequences of the Japanese wood mouse, Apodemus speciosus. Zool Sci 25: 273-285

Tomozawa M, Tomida H, Suzuki H, Tsuchiya K (2010) Mitochondrial phylogeography and population history of the large Japanese wood mouse (Apodemus speciosus) on Sado Island, Japan. Mammal Study 35: 93-97

Tomozawa M, Nunome M, Suzuki H, Ono H (2014) Effect of founding events on coat colour polymorphism of Apodemus speciosus (Rodentia: Muridae) on the Izu Islands. Biol J Linn Soc 113: 522-535

Yamamoto M, Ohira F, Kumon F (2014) Late Pleistocene variation in lignin and fatty acids from core TKN-2004 in a small mountain basin in central Japan. Geochem J 48: 207-217

(Received October 11, 2016 / Accepted February 11, 2017) 